\title{
AUMC Dosing to Last Concentration Normalized by Surface Area
}

National Cancer Institute

\section{Source}

National Cancer Institute. AUMC Dosing to Last Concentration Normalized by Surface

Area. NCI Thesaurus. Code C92328.

The area under the moment curve (AUMC) from the time of dosing to the last

measurable concentration divided by the surface area. 